\author{
Cadernos de \\ ESTUdOS LINGüĺsticOS - (56.2), Campinas, Jul./Dez. 2014
}

\title{
FAMILY RESEMBLANCE AND THE SYNCRETISM OF REFLEXIVE MARKS: THE CASE OF GEORGIAN
}

\author{
JOÃO PAULO LAZZARINI-CYRINO \\ Universidade de São Paulo
}

\begin{abstract}
RESUMO: A marca pré-radical verbal -i- do georgiano levanta uma série de problemas para abordagens gerativistas e cognitivistas do sincretismo das marcas reflexivas. Trata-se de uma marca com funcionalidades médio-passivas (Nash, 2002) que ocorre também em reflexivas plenas (Amiridze, 2006) e como marcação de aspecto perfectivo para verbos atélicos (Holisky, 1981). Neste artigo mostro que qualquer análise baseada em redução de valência - o caminho mais óbvio para se tratar esse tipo de fenômeno - é incapaz de dar conta da distribuição de -i-. Alternativamente, proponho que a vogal está distribuída de acordo com um conjunto wittgensteiniano de semelhança por famílias (Familienähnlichkeit).
\end{abstract}

Palavras-Chave: sincretismo, voz-média, reflexividade

ABSTRACT: Georgian verbal pre-radical vowel -i- raises many issues for generative and cognitive approaches to the syncretism of reflexive marks. The vowel bears medio-passive functionalities (Nash, 2002), occurring also in full reflexives (Amiridze, 2006) and as a perfective aspect marker for atelic verbs (Holisky, 1981). In this paper I show that any analysis based in valence reduction - the most obvious path for accounting for this kind of phenomenon - is uncapable of foreseeing the distribution of -i-. Alternatively, I propose that the vowel is distributed according to a Wittgensteinian Family Resemblance (Familienähnlichkeit) set.

Keywords: syncretism, middle voice, reflexivity.

\section{INTRODUCTION}

In Georgian both reflexives and a certain class of anticausatives share the same marking, the pre-radical vowel ${ }^{1}$ (PRV) -i-:
(1) a. K'ar-i
i-gh-eb-a.
Door-NOM PRV-open-TH-3s.
'The door opens.'

\footnotetext{
${ }^{1}$ Within Georgian Grammar, the verbal pre-radical vowels hold a clear position as exponents of the category called version or kceva (meaning 'behavior'), a category that bears properties roughly related to valence. Its four described types - Subjective, Objective, Locative and Neutral - mark from the valence increasing of beneficiaries and locatives to the absence of any special valence change.
} 

b. Elene tav-s i-k'rit'ik'-eb-s.
Elene.NOM SELF-DAT PRV-open-3s3s.
'Elene criticizes herself.'

Concerning our actual knowledge, this phenomenon resembles to that of the of indo-european SE, or that of the passive agreement in greek or albanian, as seen in the data below:

(2) a. O João se machucou.

The John SE hurt.

'John got hurt'

Portuguese Anticausative

b. O João se elogiou.

The John SE praise.

'John praised himself.'

Portuguese Reflexive

(3) a. To leoforio gremiz-ete.

The bus shattered-NACT.

'The bus is getting shattered.' Greek Anticausative

b. I Maria xteniz-ete.

The Maria comb-NACT.

'Mary combs herself.'

\author{
Greek Reflexive
}

(4) a. Fëmija la-het.

Child wash-NACT.

'The child is washing.'

Albanian Reflexive

b. Dera hap-et.

Door open-NACT.

'The door is opening.'

Albanian Anticausative

This phenomenon is commonly referred to in terms of a syncretism - i.e. medio-passive syncretism - or as a Voice within the voice system of a given language, the Middle Voice (see Kemmer, 1994). Within Generative linguistics, a common approach to such phenomenon is that of the valence reduction morpheme: such syncretic marks are uniformly analyzed as valence reduction operators. This reduction may be done lexically (Chierchia, 1989; Reinhart, 1997, 2000) or syntactically (Pesetsky, 1995; Embick, 1997, 1998; Lidz,2001, among many others) ${ }^{2}$. In this context, Nash (2002) suggested that the Georgian pre-radical vowel -icould be a detransitivizing strategy. This reasoning could explain the figuring of -iin anticausatives and reflexive verbs. However, following Amiridze (2006), when taking reflexivization strategies of Georgian deeply in consideration, the status of -i- shows up again to be unclear.

${ }^{2}$ Reinhart \& Siloni (2005) propose an analysis in which Reduction can be held in the Lexicon or in Syntax depending on the language. Their version of Syntactic reduction, however, is different from those we are presenting in this paper, but also problematic for Georgian data, since it leads to similar consequences. 
Here I show that any valence reduction approach will fail to account for the distribution of the pre-radical vowel -i-. Alternatively, I show that -i- can be better understood by following the insights from Haspelmath's (2003) Semantic Maps proposal and its application to the Indo-European SE by De Schepper (2007). According to these thoughts, since the multifunctionality of a morpheme such as -i- is the result of a diachronic spread, it may not necessarily have a uniform analysis covering all its contexts of occurrence. What we see is that synchronically we are more likely to have a Wittgensteinian family resemblance phenomenon among the contexts of occurrence of the morpheme. The distribution of Georgian -i- as shown in this paper becomes particularly interesting when compared to the distribution of morphemes in other languages, showing that the spread of the syncretism among them - although having the source in different constructions they tend to pattern the same way.

\section{GENERATIVIST VALENCE REDUCTION APPROACHES TO -I-}

Without going into the matter of whether a valence reduction approach is correct either for any kind of medio-passive syncretism or only for some isolated cases in some languages, here I show that at least it does not explain the occurrence of the Georgian pre-radical vowel -i-. Valence reduction approaches come in two flavours: Lexical and Syntactical.

A typical Lexical approach to the medio-passive syncretism is that one seen in works such as Reinhart $(1997,2000)$. There, the operation of Reduction (see Chierchia, 1989) is held in the Lexicon, actuating over transitive entries:

(5) a. $\mathrm{V}\left(\theta_{1}, \theta_{2}\right)$

b. Reduction: $\mathrm{R}(\mathrm{V})<\theta_{1}>$

$$
(\mathrm{R}(\mathrm{V})(\mathrm{x})) \leftrightarrow \lambda \mathrm{x}[\mathrm{V}(\mathrm{x}, \mathrm{x})]
$$

For Chierchia (1989) anticausatives and reflexives somehow share the same semantics. Thus, the operation of Reduction would produce both reflexives and anticausatives and the SE morpheme marking them is an output of the operation. For Reinhart (2000), however, there is an important difference between unaccusatives and reflexives: although they are both intransitives in this approach, reflexives are the result of a reduction of the internal thematic role of a transitive entry, while anticausatives come from the reduction of the external thematic role. This would produce unaccusative anticausatives and unergative reflexives. A phenomenon motivating such characterization of the intransitivity of anticausatives and reflexives is seen, for instance, in Russian, where in a negation context anticausatives allow genitive subjects whilst reflexives and unergatives do not:

(6) a. Ne pojavilos' studentov.

Not showed up.SE students.GEN.

'The students didn't show up.' 

b. * Ne pomylos' studentov.
Not washed.SE students.gen.
'The students didn't wash themselves.'
c. * Ne tancevalo studentov.
Not danced students.GEN.
'The students didn't dance.'

This valence reduction approach, however, assumes that reflexives are intransitives. So, if it is to account for Georgian -i-, something must be said about a basic difference between its reflexives and anticausatives: the latter is intransitive and the former is transitive. This is evidenced by the need of the object tav in reflexives:

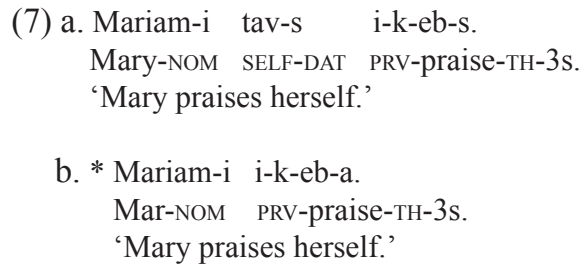

It is really important to consider that, if we are to compare -i- with $\mathrm{SE}$, Georgian reflexives with - $i$ - and tav - even if transitives - may be the correspondents to those with SE in many indo-european languages. Consider, for instance, Russian, that has two reflexive marks: the affix -sja and the full object sebja. While the former, syncretic with anticausatives, may be analyzed as a detransitivizer, it is clear that the strategy sebja does not interfere with the verbal transitivity. The question here is whether Georgian reflexives with $-i$ would rather pattern with sebja. A basic test to show that they do not do so is that of coordination ${ }^{3}$. While sebja can be coordinated with other DPs, Georgian $-\mathrm{i}-+\operatorname{ta} v$ strategy does not allow other DPs to be coordinated:

(8) Russian sebja vs. -sja coordination:

a. Anton predstavilsja $*_{i}$ Petju.

Anton introduced.SE and Pete.

'Anton introduced himself and Pete.'

b. Anton predstavil sebja i Petju.

Anton introduced himself and Pete.

'Anton introduced himself and Pete.'

3 There are some other tests that can be done to establish the distribution of these two reflexivization strategies across languages. They can be found in Lubowicz (1999) and Kapitonov (2008), which relate such distribution to different focalizations: activity focus vs. object focus. Haspelmath (2005) also brings interesting insights on such distribution across languages. 
(9) * Kal-i i-k-eb-s tav-s da tavis kmar-i.

Woman-NOM PRV-praise-TH-3s3s SELF-DAT and her.DAT husband-DAT.

'The woman praised herself and her husband.'

On the other hand, Georgian can replace the pre-radical vowel -i- with a possessive pronoun forming the POSS+tav strategy (cf. Amiridze, 2006). This strategy is more likely to pattern with sebja strategies:

(10) Kal-i a-k-eb-s tavistav-s da tavis kmar-i.

Woman-NOM PRV-praise-TH-3s3s her.DAT SELF-DAT and her.DAT husband-DAT.

'The woman praised herself and her husband.'

Hence, if Georgian -i- reflexives are really comparable to Indo-European $\mathrm{SE}$ reflexives, they cannot be explained through Lexical Reduction, since Lexical Reduction necessarily implies in detransitivization. We could then think of another approach to the syncretism that would account also for transitive reflexives featuring a mark also shared by anticausatives.

One interesting phenomenon accounted for in Embick $(1998,2004)$ is the afto- reflexives in Greek. Recalling previous data in (3) and repeated below, we see that Greek features the so called non-active agreement, which shared by anticausatives and relexives.

(11) a. To leoforio gremiz-ete.

The bus shattered-NACT.

'The bus is getting shattered.'

b. I Maria xteniz-ete.

The Maria comb-NACT.

'Mary combs herself.'

If the syncretism of Greek non-active agreement covered only the constructions above, a Lexical Reduction would straightforwardly account for it. However, it is striking that certain reflexive constructions require that the verb bear, besides the non-active agreement mark, the prefix afto-, glossed with SELF. The typical case is that of the verb katastrafo (to destroy):

(12) O Iannis afto-katastraf-ike.

The John SELF-destroy-NACT.

'John destroyed himself.'

(Embick, 1998: 9)

What Embick suggests about Greek reflexives and its relation to the nonactive agreement is that the non-active agreement (called by him non-active voice) is, by itself, incapable of reflexivizing. However, reflexivization comes up when it is combined to an inherently reflexive verb (for instance, the grooming verb xtenizo, to comb), or to a verb with afto. The generalization is seen below: 
(13) Embick's Generalization: non-active voice does not reflexivize verbs, but appears on verbs which are syntactically reflexivized by other means; i.e., by virtue of being 'Inherently Reflexive', or by virtue of afto.

(Embick, 1998: 16)

In Embick's analysis afto is considered a deep clitic anaphora in the terms of Marantz (1984) or McGinnis (1997) generated in the external argument position. The subject (i.e. O Iannis) is thus generated in the internal argument position. The derivation from this initial configuration of the reflexives in Greek will comply with the Unaccusative Analysis of Reflexives (Marantz, 1984; Kayne, 1988; Pesetsky, 1995, among others) in which the subject of a reflexive is generated internally to the verb. The movement yielded by the internal argument to the subject position satisfies binding conditions with the anaphora in the external argument, explaining the surfaced word order in a sentence such as in (12) above. Taking this analysis for Greek, it is interesting to ask to which extent is afto comparable to Georgian reflexive object tav. If tav may be considered an anaphoric object, an unaccusative analysis for Georgian reflexives may be possible and the pre-radical vowel -i- would have a similar status to that of the Greek non-active agreement mark.

Embick proposal assumes the Distributed Morphology theoretical framework (see Halle \& Marantz, 1993), a generativist model of Grammar that assumes - amongst other things - phonology is inserted after syntactic derivation. Within this framework, syntax manipulates abstract features to which phonological content may be related through correspondence rules (Vocabulary Items). Some of the features relevant for phonological insertion are, however, not manipulated by syntactic derivation, but rather inserted after it (dissociated features, see Embick \& Noyer, 2005) having no interaction with sentence's meaning, but with the phonological form generated. What accounts for the insertion of non-active agreement morphology in Greek is the insertion of a certain dissociated feature in the syntactic node $v$ (see Chomsky, 1995) whenever the external argument does not present a full DP (non-clitic or non-anaphoric). The phonological exponents of the non-active paradigm are specified to this feature.

Though assuming a transitive structure for reflexives, this approach is still of valence reduction in the sense it restricts the external argument to an anaphora. Non-active morphology is sensible to a sentence involving only one entity.

Georgian tav, if considered an anaphora (see Harris, 1981; Amiridze, 2006), could have a similar status of the Greek afto. Thus, an analysis explaining the surfacing of -i- as a phenomenon occurring whenever the external argument is not a full DP might give the pre-radical vowel a more clear status. However, one must regard that, as an exponent of what is called Subjective Version, besides reflexives and anti-causatives, -i- should surface in constructions such as the following: 


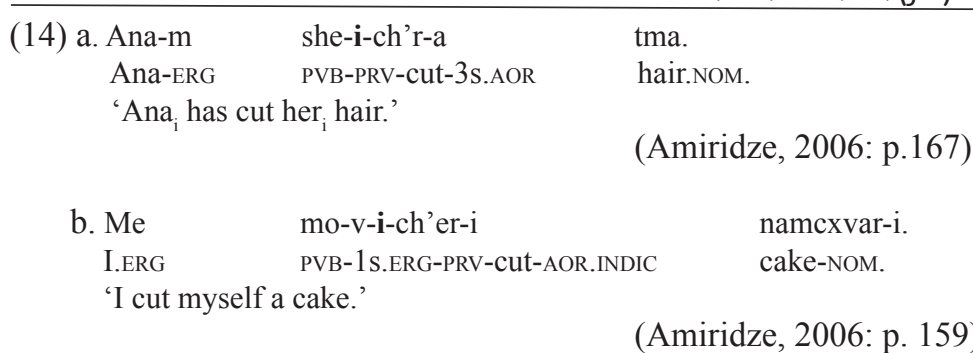

(Amiridze, 2006: p. 159)

What we see in both constructions is that they are transitive with two different entities as verbal arguments. And there surfaces the morpheme -i-, unexpectedly, if we assume Embick's mechanism. Although at first sight the impossibility of explaining -i- may seem to be an issue to Embick's mechanism, I show below that it comes actually from considering tav as the anaphor while the element gathering conditions to figure as an anaphoric element is rather -i-.

According to Amiridze (2006), Georgian SELF-anaphora in the terms of Reinhart \& Reuland (1993) is not tav, but the complete strategy -i- + tav or its focused correspondent POSS $+t a v$. What is interesting is that if we put together both strategies, we see that the elements in complementary distribution are -iand the possessive pronoun modifying the noun tav. Assuming that it is the possessive pronoun that holds a defective set of phi-features, characterizing it as the -R element and that tav is the reflexivizing part of a POSS + tav strategy, in a $-\mathrm{i}-+\operatorname{tav}$ strategy the defective phi-holder is $-\mathrm{i}-$. Hence, the pre-radical vowel should hold a similar status to that of possessive pronouns. This becomes clear when we can replace the pre-radical vowel -i- from data above in (14) with a possessive pronoun. Possession reading would be achieved naturally and beneficiary reading (14b) could be achieved by pragmatic inference from possession.

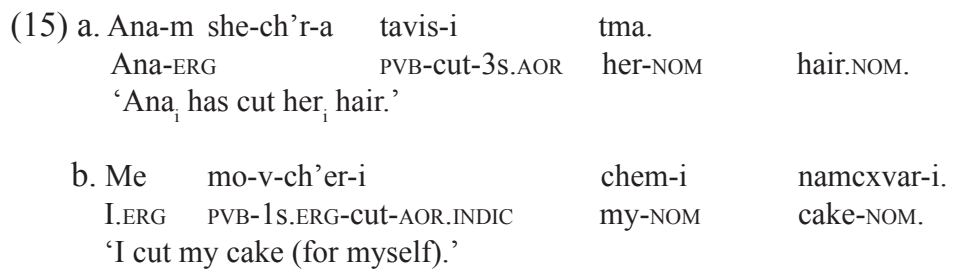

If -i- really holds similarity with pronouns, than any operator analysis of it will fail since the vowel would rather behave as argumental. Hence, valence reduction will not account for its occurrence. In the next section I will show another kind of approach to the syncretism. This approach is a more typologically oriented one with a cognitive semantics analysis, from Kemmer (1994). 


\section{A MIDDLE VOICE MARKER APPROACH TO -I-}

In the previous section I have shown two flavors of generativist analysis for the medio-passive syncretism based on valence reduction, one Lexical and one Syntactic. Both analyses failed in some extent to account for the occurrence of Georgian pre-radical vowel $-\mathrm{i}$-. The reason pointed out for that was the fact that such analyses would consider -i- as an element in an operator position while under a more attentive look, the vowel seems to behave rather as a pronoun than as an operator. Here I will show Kemmer's (1994) analysis to the phenomenon of medio-passive syncretism and whether it can apply to Georgian -i-. For her this is not the case of a syncretism, but rather of a voice system on its own: the middle Voice. The middle voice marks a specific domain - the Middle Domain - delineated by a specific cognitive semantics schema. See below:

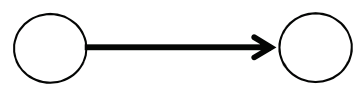

a. A transitive event:

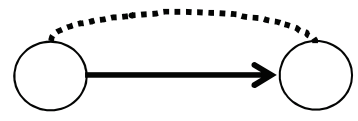

b. A reflexive event:

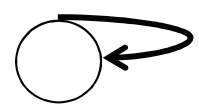

c. A middle event:

As seen above, a middle event distinguishes itself from transitive and reflexive events. A reflexive event in the sense of Kemmer (1994) is different from what we have considered by now. For Kemmer, strategies such as Russian sebja (or Georgian POSS+tav) are those producing real reflexives. Evidences for that come for example from Haiman (1983). He claims that languages having a heavy (sebja) and a light (-sja) reflexive may have the lighter form less productive and not producing an exact reflexive meaning. See below:

(17) a. On utomil

He exhausted

'He exhausted himself.'

b. On utomil-sja.

He exhausted-REFL.

'He grew weary.' sebja.

REFL.

(Cf. Haiman, 1983: 796) 
While sebja marks a truly reflexive event, the morpheme -sja marks a somehow spontaneous event, which is claimed by Kemmer (1994) to be the kind of event described by the Middle Domain. Hence, -sja in Russian is not a reflexive or anticausative mark, but rather a Middle Domain mark. Middle marks tend to occur in the following situations:

(18) Middle Situations (Cf. Kemmer, 1994)

a. Grooming or body care: wash, shave, get dressed.

b. Non-translational motion: turn, bow.

c. Change in body posture: sit down, get up, kneel down, lie down.

d. Translational motion: climb up, fly, go away.

e. Naturally reciprocal events: agree, embrace, wrestle.

f. Indirect middle: acquire, ask, request, take for oneself.

g. Emotion middle: be angry, grieve, be frightened.

h. Emotive speech actions: complain, lament.

i. Cognition middle: cogitate, ponder, think over.

j. Spontaneous events: recover, germinate, come to a stop, vanish.

Regardless of whether Kemmer (1994) supplies the light reflexive/ anticausative mark in many languages with a sufficient analysis or not, such an approach poses an important issue for Georgian. If Georgian reflexives and anticausatives showing the morpheme -i- are realizations of the same semantic domain, why are they different in terms of transitivity? The problem is that the middle situations above do not necessarily implicate on the insertion of -i- in Georgian. Rather, they are more likely to be realized in Georgian by unergative verbs usually denoting Activity Aktionsart. Such verbs are members of the traditionally described $3^{\text {rd }}$ Class, or Medial Verbs (see Hewitt, 1995).

(19) a. Ana bana-ob-s. Ana wash-TH-3s.

'Ana washes herself.' Grooming verb

b. Ana chiv-i-s , rom misi mezobeli dzalian xmauriania. Ana complain-TH-3s, that her neighbor too noisy.is.

'Ana complains that her neighbor is too noisy.' Emotive Speech Action

c. Ana dzalian zrun-av-s imis shesaxeb.

Ana too care-TH-3s that about.

'Ana cares too much about that.' Emotion Middle 
Some other are realized by unaccusative verbs, as expected, but none of them is realized by $-\mathrm{i}-+$ tav reflexivization strategy. This could suggest that both $-\mathrm{i}-+$ tav and POSS + tav strategies are more related to the conceptualization in (16b) of real reflexives than to that of (16c) of middles. In other words, $-i-$ is not necessarily related to the Middle Domain.

By now we have seen that the behavior of -i- in Georgian is fairly complex to receive a uniform analysis in terms of reduction, restricted external argument or middle voice. In the next sections I will recall the contexts of insertion of $-i$ - and show that perhaps a uniform analysis ${ }^{4}$ of - $\mathrm{i}$ - covering all of those contexts is not the right path towards the comprehension of the distribution of this pre-radical vowel.

\section{MAPPING OF THE PRE-RADICAL VOWEL -I-}

In the previous sections we saw that $-\mathrm{i}$ - is a pre-radical vowel that could be related to a medio-passive syncretism, such as that of Indo-European SE, due to its occurrence in anticausatives and reflexives. However, the clear surfacing of -iamong transitive verbs poses obstacles to valence reduction analyses and it seems clearly not be the exponent of a middle marker in all of its occurrences. Bearing in mind this panorama, one can ask if the phonological cover -i- has really the same meaning in every context it surfaces. To address to such an issue, let us first consider relevant contexts of occurrence of the pre-radical vowel $-i$-.

The pre-radical - $\mathrm{i}$ - is mentioned in three moments within Georgian traditional descriptive grammar: as a subjective version marker, as a class II verbal marker and as a class III future/aorist marker. First, considering that subjective version is characterized by the action being held on the benefit of its subject, there it undoubtedly bears reflexive meaning allowing constructions such as those below:

a. Ana-m she-i-ch'r-a tma. Ana-ERG PVB-PRV-cut-3s.AOR 'Anai has cut heri hair.'

hair.NOM.

(Reflexive Possession)

(Amiridze, 2006: p.167)

b. Me mo-v-i-ch'er-i namcxvar-i.

I.ERG PVB-1s.ERG-PRV-cut-AOR.INDIC cake-NOM. 'I cut myself a cake.'

(Reflexive Beneficiary)

(Amiridze, 2006: p. 159)

$\begin{array}{ll}\text { c. Elene } & \text { tav-s } \\ \text { Elene.NOM } & \text { self-DAT } \\ \text { 'Elene praises herself' }\end{array}$

i-k-eb-s.

PRV-praise-TH-3s3s.

(Common Full Reflexive)

\footnotetext{
${ }^{4}$ When negating a uniform analysis for -i- I do not mean that there should be more than one -i- as a lexical item, but rather that this item is not the realization of a uniform syntactic/semantic property within all its contexts of occurrence. This will become clear in section 5 .
} 
Reflexivity is often semantically related to middle meanings, since they share some common aspects of conceptualization (see Geniusiene, 1987; Haspelmath, 1987 and Kemmer, 1994). Since Class II verbs are regarded as anticausative and passive within Georgian Grammar (vnebiti gvari, Shanidze, 1973 and also Harris, 1981; Hewitt, 1995) and such readings are framed within the middle domain, there is semantically no problem on considering -i- as the same morpheme in Class II and Subjective version.

Haspelmath (2003) draws a map of common reflexive/middle functions among languages covering full reflexives, grooming actions, naturally reciprocal, anticausative, deobjective, potential passives and passives:

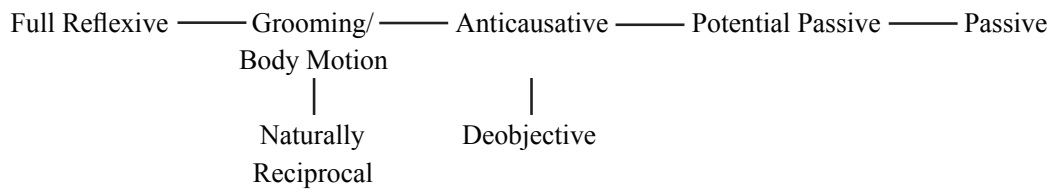

This map of functions is relevant to describe the distribution of reflexive/ middle marks among languages. For instance, romance SE and Russian -sja may cover some common but also some different areas of the map:

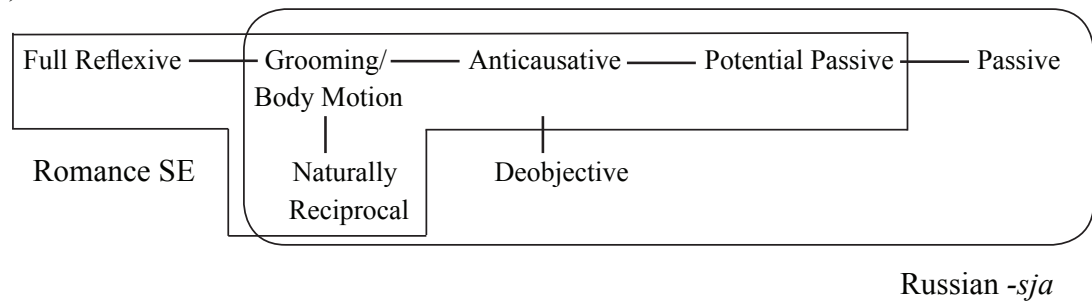

To establish the areas covered by -i- on such a map, we must test which of these contexts are actually covered by -i-. Passive contexts will necessarily involve an agent, thus, if -i- is to figure in Passives, there must be possible to show the agent of the event through some kind of clause. This is possible with Georgian Class II verbs, where agents can be introduced by the mier postposition:

$\begin{array}{llll}\text { (23) K'ar-i } \quad \text { i-gh-eb-a } & \text { mdivn-is } & \text { mier. } \\ \text { Door-NOM PRV-open-TH-3s } & \text { secretary-GEN } & \text { by. } \\ \text { 'The door is being opened by the secretary.' } & \end{array}$

Potential passives correspond to Kemmer's dispositional middles or to Keyser \& Roeper (1984)'s middle constructions. These constructions mean that the subject can undergo verbal action in some way. This is typically tested with an adverb such as 'easily' in the sentence 'the door opens easily'. Hewitt (1995) says that Class II verbs are commonly used to mean that the subject can be 'verbed'. For instance, se below: 


\section{(24) Es ts'ign-i i-targmn-eb-a.}

This.NOM book-NOM PRV-translate-TH-3s.

'This book can be translated.' (lit. this book translates).

The sense meant by the construction above patterns with the description found in Kemmer (1994) and Keyser \& Roper (1984). Thus, it is sufficient to consider Georgian -i- does mark Potential Passives. Deobjectives are contexts found in Russian, which express actions such as 'the dog barks'. Such contexts are commonly expressed by Class III unergative activity verbs in Georgian: q'eps - sm. barks; t'ir-i-s - sm. cries. Anticausatives, on another hand, are very productive with Georgian pre-radical vowel $i$-, as we have been showing throughout this paper.

Grooming, Body Motion and Naturally Reciprocal events are generally not Class II or marked by subjective version in Georgian (see Amiridze, 2006). One might regard, however, that their figuring in other classes may result from the fact they're usually activities in terms of Aktionsart. Nevertheless, some body motion verbs without an activity meaning, such as to sit down (jd-eb-i) clearly comply with Class II morphology, though there is no figuring of -i-.

Concerning the markings of Class II verbs in Georgian, we have besides $-\mathrm{i}-$, the suffixal mark -d- and markerless Class II verbs. These latter verbs have a limited number in Georgian and are non-productive in other Kartvelian languages (See Tuite, 2009). I believe the lack of characteristic morphology within some Georgian Class II anticausative verbs may be due Haspelmath's (1993) generalization that more naturally spontaneous events tend to be unmarked in a language. The suffixal mark -d-, on the other hand, have different explanations. Tuite (2009), for instance, regards that -d- typically marks change of state by deriving deadjectival anticausatives and also marks inchoation, by deriving unaccusatives from Class III medial verbs. Hewitt (1995) generalizes some morphological requirements for the surfacing of -d-instead of -i-: usually -d- figures on verbs that have its transitive counterpart with the - eb theme, show vowels in their roots and also the neutral version marker -a-. For this work we will not take into account this phenomena. This is because they seem not to interfere on the fact that the pre-radical vowel -i- of Class II verbs is related in meaning to that of Subjective Version transitives.

Recalling our mapping of the contexts of insertion of -i-, the last function to be discussed is that of Full Reflexive. Full Reflexives are those characterized by the conceptualization represented in (16b). According to Kemmer (1994), these are typically transitive, what complies with the basic characteristic of Georgian reflexives with -i-: they require the tav object. Hence, within full reflexives, -iseems to mark the co-indexing of two arguments that are the same entity. This entails that -i- marks a subject that is an entity affected by the verbal event. Other contexts related to subjective version may be grouped as related to Full Reflexives (Possessive Reflexives and Beneficiary Reflexives), since they are transitive too and still show that the subject is somehow affected by the verbal event it produces, however in different extents. 
The resulting map for Georgian -i- is the following:

(25)

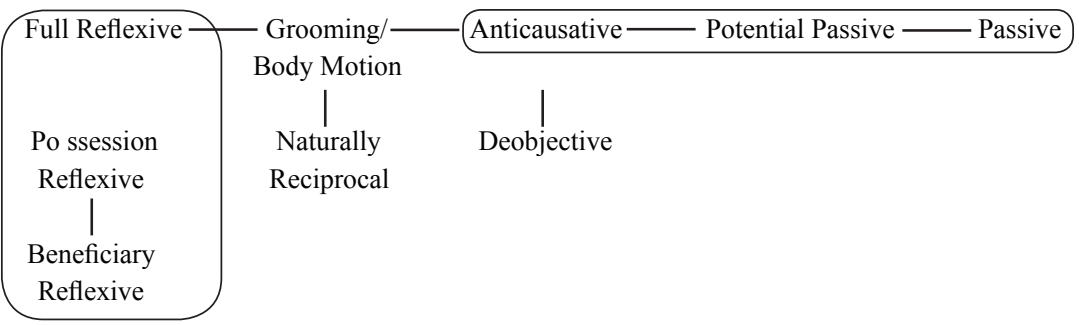

Since we considered Grooming/Body Motion as non-typical contexts of surfacing of -i-, we have a strange output concerning the semantic map of -i-: a single morpheme occupies two different regions of the map. The tricky behavior of -i- will be confirmed as we explore the third moment in which it is mentioned within Georgian grammar: as a future/aorist marker of Class III unergative verbs.

(26) a. Bavshv-i tamash-ob-s balax-ze.

Child-NOM play-TH-3s grass-on.DAT.

'The child plays on the grass.'

b. Bavshv-i i-tamash-eb-s balax-ze.

Child-NOM PRV-play-TH-3s grass-on.DAT.

'The child will play on the grass.'

c. Bavshv-ma i-tamash-a balax-ze.

Child-ERG PRV-play-3s.AOR grass-on.DAT.

'The child played on the grass.'

Georgian Class III verbs are those syntactically unergative and aspectually activities (see Amiridze, 2006). What is interesting about this class is that, differently from Class I (transitives) and Class II (unaccusatives), it cannot take preverbs to mark the perfective aspect of future and aorist tenses (see Holisky, 1981). Rather, they mark perfective aspect with the pre-radical vowel -i-. An important insight about this is that of Shanidze (1973) that, regarding the fact that in the past Class 3 verbs featured only in the present subseries, subjective versioned transitives were borrowed from Class 1 to supply the lack of the future and the aorist series. This is evidenced when taking the form a-cxovr-eb-s (X makes Y live), which is a Class 1 verb. See below:

(27) K'ot'e-m k'arg-ad a-cxovr-a col-shvil-i.

Kote-ERG good-ADV VER-live-3SBJ wife-child-NOM.

"Kote gave a good life to his wife and child."

(cf. Hewitt, 1995) 
The subjective versioned acxovrebs (i-cxovrebs) would have a meaning of live by oneself, which, if taken intransitively, would perfectly supply the future and aorist gap of the Class 3 correspondent cxovrobs. Nowadays, however, $i$ - ... - eb forms do not seem to be recovered by the speakers as coming from subjective versioned Class 1 verbs.

Another interesting fact on the usage of -i- as an aspect mark is that of the alternation of -i- and -e-. In Class II verbs marked by -i-, the pre radical vowel can be replaced by -e- to license an indirect object:

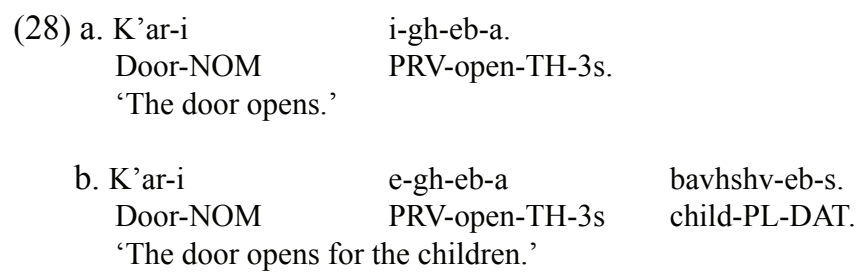

In respect to aspect marking, we see the surfacing of both -i- and -e-. While the pre-radical vowel -i- marks perfectiveness among Class III verbs, the pre-radical vowel seems to do the same among Class IV verbs:

$\begin{array}{llll}\text { a. Bich'-s u-q'var-s es } & \text { gogo. } & \\ \begin{array}{l}\text { Lad-DAT } \\ \text { 'The boy loves this girl.' }\end{array} & \text { girl.NOM. } \\ & & \\ \text { this.NOM } & & \\ \text { c. Bich'-s } \quad \text { e-q'var-eb-a } & \text { es } & \text { gogo. } \\ \text { Lad-DAT } & \text { PRV-love-TH-3s } & \text { this.NOM } & \text { girl.NOM. } \\ \text { 'The boy will love this girl.' } & & \end{array}$

Class IV verbs are characterized by an inversion, in which the subject takes dative case, while the object takes nominative. To license an oblique argument without postposition, an objective or locative version marker is required for these verbs in the present. Their future (and aorist) forms are curiously formed with the -e- pre radical vowel, that reserved to unaccusatives with indirect objects. Class IV verbs are aspectually statives, which mean that telicity is also not something to be conveyed by them, justifying the lack of preverbs on their future and aorist tenses.

If Shanidze (1973) is correct when saying that futures and aorists of Class III verbs are formed with a corresponding Class I subjective versioned verb, then we are safe to say that the subjective version morpheme -i- is the same of Class II verbs: the -i- sister within Class II verbs, -e-, also bears the same property of tense modification. This results in a very strange map of the distribution of -i-, since it figures in unrelated contexts: 


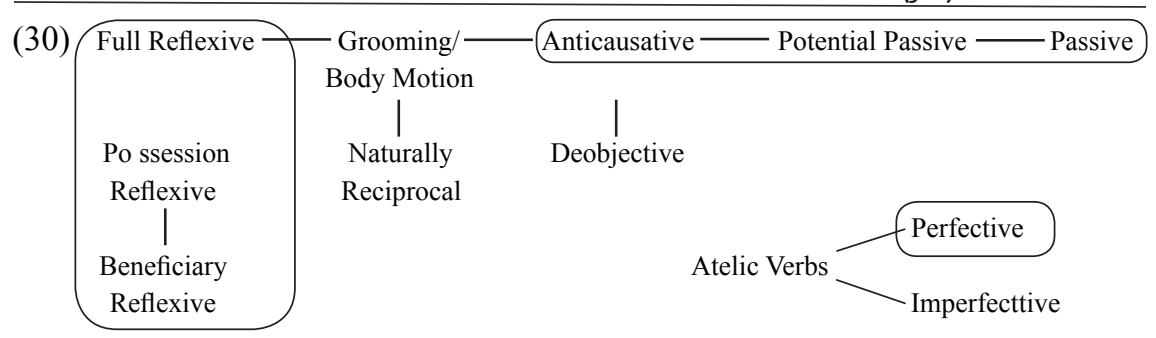

In the next section we will see how such a situation can be explained.

\section{FAMILY RESEMBLANCE AND THE SYNCRETISM OF -I-.}

When analysing the indo-european SE, De Schepper (2007) faced the duality problem of the morpheme/clitic: it expresses both an anaphora - occurring in reflexive contexts - (Dobrovie-Sorin, 1998; Steinbach, 1988) and an argument reduction mark (Reinhart \& Siloni, 2005) - occurring in middle/inherent, passive and anticausative contexts. This situation remarkably resembles to that of Georgian -i-: while clearly marking transitive verbs, acting as an anaphora/possessive pronoun - in the case of the Reflexive Contexts - it also marks clearly intransitive verbs.

From De Schepper (2007) we can take the explanation for the similarities between contexts of insertion of Indo-European SE was given in a sense contexts of insertion of SE may be related by different features in a family resemblance chain. In the schema below we can see this from the fact that Reflexive SE is only linked to intransitive contexts of SE by some property shared with inherent SE. The same phenomenon also occurs with Passive SE, which is only linked to intransitive contexts by a property shared with Ergative SE.

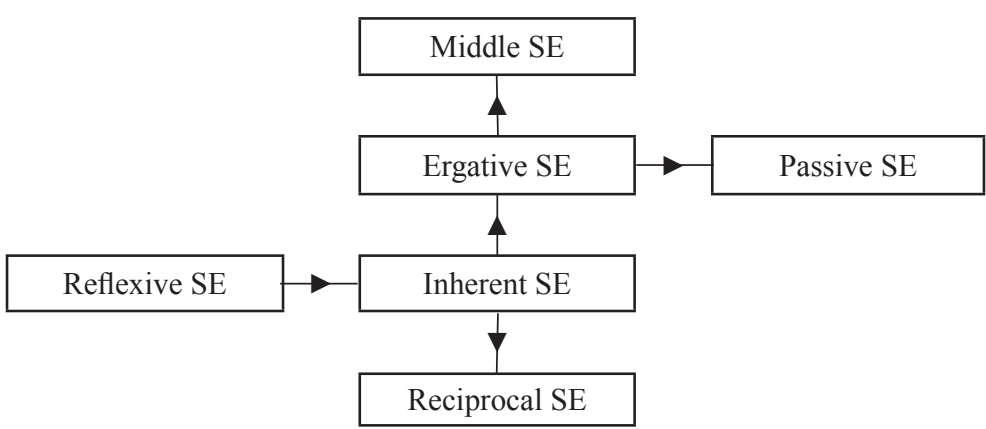

This representation has an important difference from that of Haspelmath's (2005): it shows in parallel contexts of different grammatical valence. Reflexives, which are truly transitive, and Passives, which are - at least, semantically - transitive, are shown in different columns, showing that they may be related to intransitive verbs by sharing a specific property with one of the intransitive classes. 
Bringing our attention back to Georgian -i-, the gaps of its distribution seen in a map as in (30) are emblematic of the fact something else is, in parallel, regulating its distribution. In fact, two dimensions seem to be crucial to establish the distribution of Georgian -i-. Let us call them ergativity and aspect. The dimension of ergativity can be described in terms of the affectedness of the subject of the verb. On the [-ergative] side of the scale we find transitive and unergative verbs, followed by reflexives, which - accordingly to Kemmer (1994) - are conceptualized as transitives and the affectedness seem to be driven all towards the object. On the [+ergative] side of the scale we find passives, followed by potential passives and anticausatives. On the other hand, the dimension of aspect is related to telicity and perfectivity. Let us state the aspect scale follows this rating: imperfective atelicity $<$ perfective atelicity $<$ imperfective telicity $<$ perfective telicity. Imperfective atelic verbs are the less aspectually marked verbs in the language: no pre-radical - $\mathrm{i}$ - and no preverb. Perfective telic verbs are the most marked: pre-radical vowel -i- and preverb. See the map of -i- below:

[-Ergative] [+Ergative]

\begin{tabular}{|c|c|c|c|c|c|c|}
\hline$[+\mathrm{T} ;+\mathrm{P}]$ & Common & \multirow{3}{*}{\begin{tabular}{|l} 
Poss/Benef \\
Reflexives \\
Imperfective \\
Unergative
\end{tabular}} & \multirow{2}{*}{$\begin{array}{l}\text { Full } \\
\text { Reflexives } \\
\qquad\end{array}$} & \multirow{2}{*}{$\begin{array}{l}\text { Trans.- } \\
\text { Middles }\end{array}$} & \multirow{2}{*}{\multicolumn{2}{|c|}{$\begin{array}{ll}\text { Anticausative } & \text { Potential-Passive } \\
\text { Passive }\end{array}$}} \\
\hline$[+\mathrm{T} ;-\mathrm{P}]$ & Transitive & & & & & \\
\hline$[-\mathrm{T} ;+\mathrm{P}]$ & & & $\left.\right|_{\substack{\text { Imperfective } \\
\text { Grooming }}}$ & $-i-$ & $\begin{array}{l}\text { In.Obj. Antic. } \\
\text { Imperfective } \\
\text { Psychic (C4) }\end{array}$ & -e- \\
\hline ;-P] & & $\begin{array}{l}\text { Perfective } \\
\text { Unergative }\end{array}$ & $\begin{array}{l}\text { Perfective } \\
\text { Grooming }\end{array}$ & & $\begin{array}{l}\text { Perfective } \\
\text { Psychic (C4) }\end{array}$ & \\
\hline
\end{tabular}

The proposed map above in (32) can represent the contexts of insertion of -i- in relation with the scales of aspect and ergativity. Notice that, differently from the map in (30), here we have no gaps. Among telic verbs we have included those constructions with common transitive verbs as the prototypical [-ergative] constructions, since the subject is clearly not affected by the events denoted from such verbs. Within the contexts covered under the label subjective version - transitive verbs marked with -i- - can see a variation in terms of the property ergativity. Possession/Beneficiary Reflexives can be considered the less ergative from such contexts, since its subject is not entirely nor directly affected by the event and its agentivity is very clear. Full Reflexives, marked by $-\mathrm{i}-+$ tav are one step further in terms of ergativity: since the subject and the object refers to the same entity, the agentivity of the subject becomes less clear and its affectedness more patent.

A third context under the subjective version household is the one I called Transitive Middles. This refers to transitive verbs marked with -i- not carrying reflexive meaning, but rather some kind of internal causation. This is the case of the verbs $-i-c^{\prime} q$ ' $-e b$ (to start), $-i-d z i n-e b$ (to go to sleep) or -i-smen (to listen). See the examples below: 
(33) a. Me lekcia da-v-i-c'q'-e.

I.ERG lecture.NOM PVB-1s-PRV-start-AOR.

'I started the lecture.'
b. Mama-shen-i
ver
g-i-smen-s.
Father-your-NOM NEG.POT
'Your father can't listen to you.'
2s-prv-listen-3s.

These may be considered even further then full Reflexives in terms of ergativity, since the subject is clearly an experiencer of the event, and also an internal causer of it. The object, on another hand is not within the domain of possession of the subject, nor means a benefit for it, it rather means the theme of the event.

The three other contexts of occurrence, Anticausative, Potential Passive and Passive are established in the same order as that considered in the literature (Haspelmath, 2003; Kemmer, 1994). With the same status of Anticausatives, however, I have put those anticausatives marked with -e-, which show indirect objects.

Atelic verbs are split up in this representation into perfective and imperfective contexts, since -i- can only be present in perfective atelic verbs. Among these verbs, normal class III verbs, unergative, such as musha-ob (to work) or tamash-ob (to play) can be considered as the most closely to [-ergative]. Although some low degree of affectedness of the subject of such verbs may be detected, it is crucial that the subject is an agent. The deobjective verbs mentioned by Haspelmath (2003) may also be included into this family for Georgian, as formerly discussed. More closely to [+ergative] are the Grooming verbs (and also some emotional middles) marked by the Class III morphology. Verbs such as bana-ob (wash oneself) really mean the subject is agent and patient of the verbal event, seeming to be different from Full Reflexives only in terms of telicity.

Class IV verbs, generally stative or psychic, comply with a transitive structure in which the subject, marked with DAT, is an experiencer whilst the nominative complement, the object, is a theme. This agentless characteristic aligns them with anticausatives and puts them mostly close to [+ergative]. Since Class IV verbs have oblique arguments (the subject), their perfective form will show the morpheme -e-, which is the same marking anticausatives with oblique arguments.

It is very difficult to pose a uniform analysis which account for every context in which -i- is inserted. For instance, while among telic verbs it is clear that verbs without any trace of ergativity ([-ergative] verbs) should bear the morpheme -i-. However, this is not necessarily true for atelic verbs, which will have -imarking their perfective forms independently of the ergativity dimension. Also the distribution of the pre-radical vowel -i- in some contexts does not seem to be strictly and systematically related to semantic/syntactic characteristics, but with inheritance from other similar contexts. One case is that of the atelic verbs, hypothesized by Shanidze (1973), which we mentioned formerly. Another is the case of Class II, unaccusative verbs. 
As told before, there are three kinds of Class II verbs: unmarked, suffixal and prefixal. The pre-radical vowel -i- only occurs in the latter kind. Let us recall the fact that unmarked unaccusatives are generally conceptualized as naturally spontaneous events (Haspelmath, 1993) and that suffixal Class II verbs are told to have a systematic context of insertion (deadjectivals for Tuite, 2009; morphophonological characteristics for Hewitt, 1995). The rest of the unaccusatives of the language, generally anti-causatives, which are not naturally spontaneous events nor do comply with the suffixal conditions would need a mark. The odds that such mark is probably borrowed from what I've called Transitive Middles are very high. Regard that Transitive Middles were described as always involving a nonagentive/non-causative subject. with -i-:

Below we schematize the properties shared by each link between telic verbs

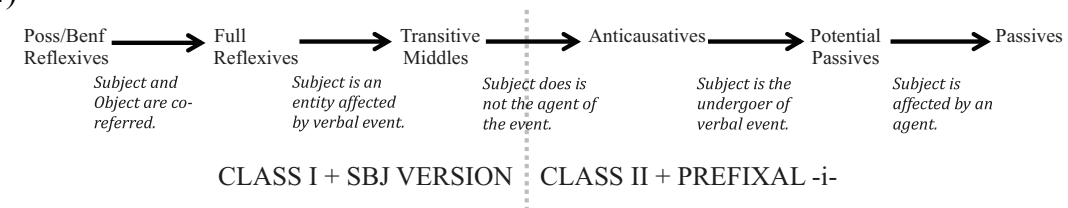

On the spread of -i- to mark perfectivity of atelic verbs it is not clear, diachronically speaking, which context motivated -i- to mark aspect. Shanidze's insight (see data in 27) uses -i- as a valence reduction morpheme to form a somehow inherent reflexive counterpart of the causative perfective form $a$-cxovr- $a$ (he made live) that could act as a perfective counterpart for imperfective/atelic cxovrob-s (he lives). In this sense, the spread started from a Common Reflexive to form perfectives of atelic verbs. The map in (32), however, works in a synchronic sense, linking properties that are being synchronically shared. Hence Grooming Verbs are more directly related to Full Reflexives in that map: they are almost the same event, with the exception that the former are necessarily atelic. Other unergative verbs are related to Poss/Benef Reflexives because of the quality of their subject, which is necessarily agentive. The spread can be represented as follows:

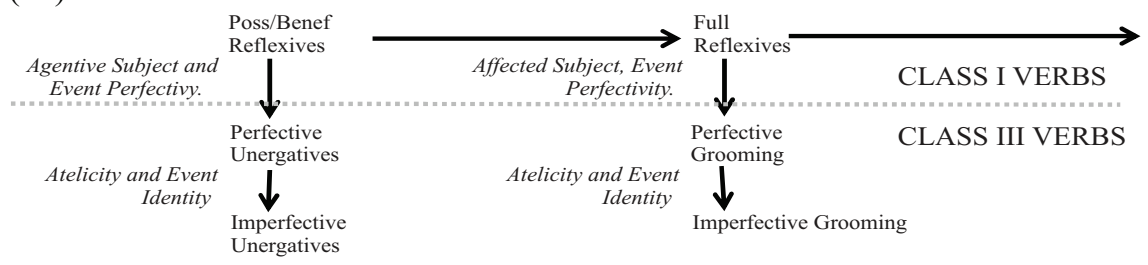

Class IV verbs have a more clear relationship with Anticausatives, especially with those with indirect objects, marked with -e-. As discussed formerly, Class IV verbs and Anticausatives share the property of bearing non-causative arguments. 
What we have shown here is that the pre-radical vowel -i- (and its contextual allomorph -e-) can be understood not as a marker of a single syntactic/semantic property, but rather of a chain of property sharing between similar contexts. It is interesting that this chain can be understood as a case of Wittgensteinian Family Reseblance within Grammar. In this case, morphemes may be associated with families of grammatical constructions whose elements are related not by a uniform property, but by inherited properties from one element to the other. This can be represented as below:

(36) A Family Resemblant Set:

\author{
Element 1: A, B, C, D. \\ Element 2: A, D, E F. \\ Element 3: D, E, F, G. \\ Element 4: F, G, H, I. \\ Element 5: G, H, I, J.
}

Although not canonical within theoretical linguistics, Family Resemblance can be a good tool for the description and understanding of morphological syncretism or multifunctionality. Differently from stating that we have in the grammar two or more identical morphemes associated with independent roles, in this case we can have an elegant non-uniform analysis based on a single morpheme.

\title{
6. CONCLUSION
}

In this paper we have shown that the Semantic Maps approach to the Georgian pre-radical vowel -i- can represent some interesting insights on the description of the vowel, such as its contexts of occurrence, its relation to an ergativity property and to telicity and grammatical aspect. From such a representation it is possible to hypothesize the diachronic spread of the morpheme to its contexts of occurrence nowadays and furthermore, to relate its occurrence synchronically to a possible case of Family Resemblance within Grammar.

\section{$\overline{\text { 7. REFERENCES }}$}

AMIRIDZE, N. (2006) Reflexivization Strategies in Georgian. Phd Diss. University of Utrecht.

ANDERSON, G. \& GUREVICH, O. (2005) Toward a Typology of Version: Formal and Functional Perspectives. Ms.

DE SCHEPPER, K. (2007) Reflecting the Past: Mapping the development of the Indo-European SEform. In: B. Los and M. van Kopp (eds.) Linguistics in the Netherlands, 2007. Amsterdam: John Benjamins, 211-222. 
DOBROVIE-SORIN, C. (1998) Impersonal Se Constructions in Romance and the Passivization of Unergatives. Linguistic Inquiry, 29, 399-437.

CHIERCHIA, G. (1989) A Semantics for Unaccusatives. Ms.

CHOMSKY, N. (1995) The Minimalist Program. Cambridge, Mass: MIT Press.

EMBICK, D. (1998) Voice Systems and the Syntax/Morphology Interface. HARLEY, H. (org). The proceedings of the Penn/MIT workshop on Aspect, Argument Structure and Events. MITWPL.

EMBICK, D. (2004) Unaccusative syntax and verbal alternations. In: ALEXIADOU, A., ANAGNOSTOPOUlOU, E. e EVERAERT M. (orgs.) The Unaccusativity puzzle. Oxford University Press.

GENIUSIENE, E. (1987) The Typology of Reflexives. Berlin: Mouton de Gruyter.

HALLE, M. \& MARANTZ, A. (1993) Distributed Morphology and Pieces of Inflection. In: HALE, K. \& KEYER, S. (orgs) The view from building 20: Essays in Linguistics in Honor of Sylvain Bromberguer, MIT Press, Cambridge, MA, 111-176

HARRIS, A. (1981) Georgian Syntax: A Study in Relational Grammar. Cambridge: Cambridge University Press.

HASPELMATH, M. (1987) Transitivity Alternations of the Anticausative Type. Arbeitspapiere N. F. 5. Cologne, Germany: University of Cologne.

HASPELMATH, M. (1993) More on the typology of inchoative/causative verb alternations. In: Comrie, B. and Polinsky, M. (eds.) Causatives and Transitivity. Amsterdam: John Benjamins.

HASPELMATH, M. (2003) The Geomerty of Grammatical Meaning: Semantic Maps and CrossLinguistic Comparison. The new psychology of language: cognitive and functional approaches to language structure, vol 2. Ed. By Michael Tomasello, 211-42. Mahwah, NJ: Lawrence Erlbaum.

HEWITT, G. (1995) Georgian: A Structural Reference Grammar. Amsterdam: John Benjamins.

HOLISKY, D. A. (1981) Aspect and Georgian Medial Verbs. Delmar, NY: Caravan Press.

KAPITONOV, I. (2008) Russian binding Issues. Ms.

KAYNE, R. (1988) Romance se/si, GLOW newsletter 20.

KEMMER, S. (1994) Middle Voice, Transitivity and the Elaboration of Events. In: Fox, Barbara \& Hopper, Paul: Voice Form and Function. Amsterdam: John Benjamins.

LIDZ, J. (2001) The Argument Structure of Verbal Reflexives. Natural Language and Linguistic Theory 19.2: 311-353.

MALDONADO, R. (2002) A media voz: problemas conceptuales del clítico SE en español. México: Instituto de Investigaciones Filológicas, UNAM.

MARANTZ, A. (1984) On the Nature of Grammatical Relations, MIT Press, Cambridge, Mass.

NASH, L. (2002) Entre la Flexion et le Verbe: Syntaxe, Morphologie, Acquisition. Habilitation Thesis.

PESETSKY, D. (1995) Zero Syntax: Experiencer and Cascades, MIT Press, Cambridge Mass. 
Cadernos de ESTUDOS LINGüísTICOS (56.2) - Jul./Dez. 2014

REINHART, T. (1997) Syntactic effects of lexical operations: reflexives and unaccusatives.” In: UiL OTS Working Papers, Univeriteit Utrecht

REINHART, T. \& SILONI, T. (2005) The Lexicon-Syntax parameter: Reflexivization and other arity operations. Linguistic Inquiry, 36: 389-436.

SHANIDZE, A. (1973) Kartuli Gramatiki Sapudzlebi, 1: Morpologia. Tbilisi: Tbilisi State University Press.

STEINBACH, M. (1998) Middles in German: The Syntax and Semantics of Transitive Reflexive Sentences. PhD Diss., Humboldt University, Berlin.

TUITE, K. (2009) The Kartvelian Suffixal Intransitive. Bremen Festival of Languages. 